\title{
The Diversifying Academic Profession?
}

\author{
ULRICH TEICHLER \\ International Centre for Higher Education Research, University of Kassel, \\ Germany. E-mail: teichler@incher.uni-kassel.de
}

Experts agree: higher education has to diversify continuously. Most prominently, Martin Trow had argued that 'universal higher education' and 'mass higher education' sectors had to serve the 'new' students while protecting 'elite higher education'; Burton Clark pointed out that the university is functionally 'overburdened' if it does not become entrepreneurial in pursuing specific strategies. But the countervailing forces to diversification grow as well: 'academic drift' and initiative competition for being ranked among 'world-class universities' prevail, and intra-institutional diversity according to study programmes and departments has not gained popularity either. Do scholars themselves become key carriers of diversification? Substantial variety in research productivity is by no means new. Is inter-individual diversity within higher education a viable future of diversification? Do the data of the comparative studies on the academic profession suggest that strategic options of individual professors are salient?

\section{Introduction}

The diversity discourse

In a recent study on major trends of higher education in Europe as well as major trends in higher education research, 'diversity' was identified as one of the most persistent and salient issues in the discourse on higher education for a period of about five decades. 'Diversification' often is viewed as a desirable or inadvertent trend in higher education in response to the expansion of student enrolment as well as the 'explosion' of systematic knowledge. A closer view, however, reveals that the trend is less consistent and continuous than one might expect when looking at the growth of higher education and assuming, in tune with system theory, that growth is likely to lead to diversification. Among others, higher education policies might favour an enormous growth of variety within higher 
education or, conversely, a moderate degree of diversity. Moreover, diversity reinforces efforts to imitate the most prestigious sectors of higher education and eventually, if these efforts are successful to a certain extent, diversity might be reduced. ${ }^{2,3}$

The discourse on 'diversity' focuses on two issues: first, the factors contributing to diversity in higher education, e.g. dynamics of the knowledge systems and changing societal pressures, and, second, the patterns of diversity in higher education, e.g. various types of higher education institutions or ranks of reputation. ${ }^{4}$ In the framework of the analysis presented in this article, the latter issue will be highlighted.

\section{Teaching-related diversification patterns in the higher education system}

Most experts believe that the changes in higher education systems strongly reflected changes in the student population. Consequently, the various emerging patterns were primarily discussed as responses to the changing teaching functions of higher education. Thereby, attention was paid primarily to differences between institutions of higher education and study programmes. Six dimensions of diversity played a role both in the debates and the actual developments of national higher education systems.

(1) Sectors of higher education. In the process of increasing rates of student enrolment, Martin Trow's concept of 'elite', 'mass' and 'universal higher education' has become the most widely known concept. According to Trow, the driving force of diversification is the quantitative expansion of student enrolment, which leads to a greater diversity of the overall student body in terms of motives, talents and job prospects. The higher education system responds to the increasing diversity of the student body by a diversification according to sectors of higher education: the 'elite sector', the 'mass sector' (and finally the 'universal sector') ${ }^{5}$ trends and policies towards sector diversification help to protect the elite sector from dilution and to serve the new students better in the 'mass sector' according to their motives, abilities and job prospects.

(2) Types of higher education institutions. While Trow left open to what extent such a sector diversity is carried by institutional types, programme types, levels of programmes, or levels of quality and types of profiles of higher education institutions, the discussion in Europe (in the 1960s and 1970s) initially concentrated on types of higher education institutions. The polytechnics in the UK, the IUTS in France and the Fachhochschulen in the Federal Republic of Germany were the most prominent examples for such an interinstitutional diversification. These new 'non-university' institutions 
were expected to offer shorter study programmes with an emphasis on applied knowledge, and the teaching staff at these new institutions were exclusively or predominantly in charge of teaching, whereas professors at universities were equally in charge of research and teaching.

(3) Extension of the system and of institutional types. In the 1980s, the international organisations (notably UNESCO, OECD and the European Union) moved a step further towards institutional diversification by creating the definition of 'tertiary education', and by distinguishing between higher education and other tertiary education in their statistics, whereby the terms applied changed over time.

(4) Types of programmes and intra-institutional diversity. Occasional efforts were made in the 1970s to establish higher education sectors according to programmes. However, two or more types of programmes could exist within the same institution of higher education: such kinds of efforts to establish a system of intra-institutional diversity, for example, the moves towards Gesamthochschulen in Germany in the 1970s and towards a general hoegskolan system in Sweden, were less successful than those to increase inter-institutional diversity.

(5) Ranks and profiles of individual institutions of higher education. In the 1990s, terms such as 'the competitive university', 'the managerial university', 'the entrepreneurial university', and 'the world class university' spread. The individual institution of higher education was expected to be the main carrier of diversification. It was expected to sharpen its 'profile' in the wake of 'horizontal diversification' and to strive for the highest possible rank of quality and reputation in the wake of 'vertical diversification'. Practically, most attention was paid to vertical diversity, and criteria of research quality or reputation outweighed those of teaching.

(6) Levels of study programmes. With the Sorbonne Declaration of 1998 and the Bologna Declaration of 1999, the ministers in charge of higher education in the European countries moved towards a common structural model of higher education: to make levels of study programmes (bachelor, master and eventually doctors) the major formal element of diversification. Again, intra-institutional diversity was on the agenda. This does make a distinction by type of higher education institution obsolete, but the institutional types are bound to change their function. ${ }^{6,7}$

The diversification of higher education through types of institutions and programmes or individual institutions was constantly 'on the move' and 'never stable'. Although horizontal diversity was advocated, the public debate focused 
on vertical diversity. As a consequence, the less noble sectors aimed to imitate the noble ones: 'academic drift' did not only undermine horizontal diversity, but became part of the perennial contradictory strives of the various actors involved to reduce and again to widen the vertical range.

The limited influence of the research function on patterns in the higher education system

Diversification as regards the research function was embedded to some extent into the teaching and student-led diversification trends and policies discussed above. Decisions to diversify by types of higher education in Europe since the 1960s, for instance, were based on the notion that teaching and learning in higher education should be expanded more widely than research within higher education institutions. As a consequence, new 'non-university' institutions of higher education were established (often through upgrading of former advanced vocational training institutions) solely in charge of teaching, while at these institutions research was viewed as an optional individual activity of some professors at best. In addition, the currently popular emphasis on ranks of higher education institutions according to academic reputation refers more often to vertical differences in research than in teaching and learning.

Experts observe further trends of 'knowledge diversification'.

- Increasing specialisation of research. We note an increasing specialisation within and across disciplines. More specialized academic communities, fewer scholars who can claim that they are competent in the discipline as a whole, more academic journals for minute areas of specialisation, etc. ${ }^{8}$

- Diversification in the relationships between knowledge and society. Many experts observe a utilitarian drift of research, i.e. (a) a substantial increase of systematic knowledge visibly linked to practical problemsolving and technology development (applied research, practically relevant research, development) in contrast to limited growth, stagnation or even decrease of 'basic research', (b) a blurring of the distinction between basic and applied research as well as an emergence of new inbetween types of research: 'mode 2' research, 'targeted research', etc. 9,10

These trends, however, most often are not reflected in patterns in the higher education system. Rather, they affect individual scholars or groups of scholars across all sectors of higher education and research. Only, the distinction between basic and applied research often was underscored when 'non-university' higher education institutions, initially focusing almost exclusively on teaching and learning, gradually moved towards sizeable activities of applied research; 
nevertheless, it was the teaching function that determined the distinction between universities and Fachhochschulen in German-speaking countries or similar institutional distinctions in the Netherlands, Finland, Norway, and other European countries.

\section{The diversity of the academic profession}

Prior analyses often have addressed three dimensions of diversity of the academic profession: the academic discipline, the career stage and the distinction according to institutional type discussed above.

(1) Academic discipline. The 'university' as an institution as well as titles such as 'professor' suggest that there are common elements within the academic profession. Many studies, however, have pointed out that 'cultures' of disciplines vary substantially: ${ }^{11}$ be it the 'divide' between natural sciences on the one hand and the humanities and social sciences on the other, be it the methodological distinctions between the so-called 'hard' and 'soft' sciences or between 'experimental' and non-experimental' sciences, be it disciplines emphasizing analytical knowledge versus those closely linked to professional or other problem-solving. Those distinctions have been most vividly emphasized by Kerr, who has coined the term 'multiversity' instead of 'university' by ironically pointing out that the persons employed in the university have more in common in their concerns about parking lots and heating systems than about academic issues. $^{12}$

(2) Career stages. Distinctions in career stages play a more important role in the academic profession than in most other occupations. Many years of the junior academic career are characterized by a long process of both learning and productive work. In many countries, junior academics are excluded from many rights and privileges of the professors. In Germany, for example, even the occupational category 'Hochschullehrer' does not include junior academic staff, and the constitutional guarantee of 'academic freedom' is confined, according to court rulings, to the professors. ${ }^{13}$

(3) Institutional type. Professors at research-oriented universities have to prove significant research achievements prior to being appointed as professor and are expected to be active both in teaching and research, whereby teaching should also be inspired by their role as researcher. In contrast, academics at other higher education institutions have to prove much less of prior research achievements and in some countries no research achievements at all are expected - they are 
expected primarily to be transmitters of knowledge and educators. Moreover, in many countries, junior academic staff in their formative years of both learning and productive work are primarily located at universities, ${ }^{14}$ whereas other institutions of higher education recruit primarily experienced academics for the purpose of teaching.

As a consequence, the academic profession is more heterogeneous than, for example, the engineering profession.

\section{Inter-individual diversity in higher education: a neglected theme}

However, not only between similar types of higher education institutions, but within the same individual institution of higher education (even within the same rank or the same discipline), we might notice an enormous diversity. This is occasionally referred to with respect to academic productivity: research on research production has shown that about $10 \%$ of university professors publish almost half the total number of academic publications written by university professors.

Obviously, one of the reasons for such a diversity is the fact that the academic profession is a very free profession.

- First, academics are very free in terms of 'academic freedom', i.e. the choice of themes, theories and methods of inquiry. 'Autonomy of the university' and 'academic freedom' are values held in high esteem in academia. Even if guidelines are set for academic behaviour (i.e. 'mission statements' of universities or set criteria for incentives and evaluations), most wise universities avoid a uniform enforcement in order not to suppress unexpected achievements and creativity.

- Second, academics are very free as far as the allocation of time to various functions is concerned. In most cases, teaching in classes, laboratories, etc, is the only highly regulated element of the job tasks. In most economically advanced countries professors at universities are more or less equally in charge of both teaching and research, whereby the assigned teaching load comprises not more than $10 \%$ of the normal annual working time. For example, a comparative survey undertaken in the early 1990s showed that strongly teaching-oriented university professors in Germany spent four hours on teaching-related activities (preparation, guidance, examinations, curriculum development, etc) per teaching hour, whereas strongly research-oriented professors spent only one hour of teaching-related activities per teaching hour; this shows the range of options to shape one's own job role. ${ }^{15}$

Therefore, it is interesting to explore the extent to which academics in a similar career stage and in similar conditions, as far as the major functions of their 
universities and the major elements of the work situation are concerned, opt for varied professional strategies and whether such options are relevant for many other aspects of their job role. This will be analysed on the basis of information provided by professors of research-oriented universities in Germany, Japan and the United Kingdom in comparative surveys undertaken in 1992 and 2007.

\section{The design of the secondary analysis}

Two comparative surveys of the academic profession have been undertaken so far that included more than a dozen countries each, namely the 1992 Carnegie Survey of the Academic Profession ${ }^{16,17}$ and the 2007 Changing Academic Profession Survey. ${ }^{18}$ The following analysis draws primarily from the latter study, but takes the findings of the former study into consideration as well, if identical or similar questions were raised permitting an analysis of possible change over time.

The analysis is limited to professors at research-oriented universities. This selection was made because professors more or less equally in charge of both teaching and research have more room for strategic options than professors at teaching-oriented higher education institutions as well as junior staff at all institutions of higher education.

The following analysis comprises the responses by professors from universities in Germany, Japan and the United Kingdom, all countries that represent a variety of academic traditions. Practical reasons came into play as well: from these three countries, data sets were available both from 2007 and 1992, which allowed for comparative data analysis. The analysis is based on the responses by altogether more than 2300 university professors in 2007 and more than 1600 in 1992.

The questions posed in both surveys allow us to measure the variety of options, hereafter referred to as 'academic profiles', in three dimensions.

1. Time budget. Time spent on research and teaching (percentage of weekly hours spent on teaching and on research, when classes are in session and when classes are not in session, of the total weekly hours spent on teaching and research, i.e. excluding hours spent on other tasks); the responses were grouped into three categories: $\mathrm{R}=$ time spent predominantly on research; RT $=$ about the same time spent on research and teaching; $\mathrm{T}=$ time spent predominantly on teaching.

2. Preferences. Based on responses to the question 'Do your interests lie primarily in teaching or in research?'; respondents were provided four categories in the questionnaires: $\mathrm{RR}=$ primarily in research; $\mathrm{R}=\mathrm{in}$ both, but leaning towards research; $\mathrm{T}=$ in both, but leaning towards teaching; TT $=$ primarily in teaching. 
3. Orientation. Responses to two different questions were combined to a typology of orientations: $\mathrm{Tp}=$ strong emphasis on theory, little on practice; $\mathrm{TP}=$ strong emphasis on both theory and practice; $\mathrm{tp}=$ little emphasis on both theory and practice; $\mathrm{tP}=$ strong emphasis on practice, little on theory. The analysis of this dimension is limited to 2007 because the respective questions posed in 1992 were not sufficiently similar.

In order to examine the impact of strategic options on views and actions in various areas of the professional life of the academic professions, cross-tabulations are presented of the three strategic options with variables from four thematic areas: (1) socio-biographical characteristics, (2) academic life, (3) teaching and research, and (4) institutional life.

The 2007 survey comprised a larger number of questions of these thematic areas. Therefore, separate tables are provided for the 2007 responses to the four thematic areas, while the 1992 responses are jointly presented in a single table.

The in-depth analysis undertaken examined the statistical significance of the findings. The presentation in this article, however, neither includes information of the number of responses to each question nor measures of significance in order to concentrate the readers' views solely on the core data.

\section{Diversity of the academic profiles}

As Table 1 shows, there exists a majority mode in the relationships between teaching and research among the university professors surveyed in 2007. The time allocated to research is more or less equal to that to teaching, and most professors are interested both in teaching and research, but with a stronger leaning towards research. In those respects, the body of German university professors is somewhat more homogeneous than that of professors from Japan and the United Kingdom.

However, other options are by no means rare: more than one quarter of respondents allocate most of their time to research and more than a fifth most of their time to teaching. Similarly, we note sizeable minorities both expressing interest primarily in research and indicating interest in both teaching and research with a stronger emphasis on teaching. Only a clear preference for teaching is a rare option among university professors of these three countries.

The degree of homogeneity or diversity of options did not change from 1992 to 2007. We cannot claim that the professoriate became more diverse during the period observed. However, there are shifts in the direction of the profiles. The German university professors, who leaned more strongly towards teaching in 1992, moved somewhat towards research; in contrast, the Japanese university 
Table 1. Teaching and research profile of university professors in Germany, Japan and the United Kingdom (percentages)

\begin{tabular}{|c|c|c|c|c|c|c|}
\hline \multirow[b]{2}{*}{ Profile } & \multicolumn{2}{|c|}{$\mathrm{D}$} & \multicolumn{2}{|c|}{$\mathrm{J}$} & \multicolumn{2}{|c|}{ UK } \\
\hline & 1992 & 2007 & 1992 & 2007 & 1992 & 2007 \\
\hline \multicolumn{7}{|l|}{ a. Time budget } \\
\hline More research $(\mathrm{R})$ & 16 & 24 & 51 & 23 & 30 & 33 \\
\hline Balanced (RT) & 59 & 59 & 37 & 49 & 52 & 43 \\
\hline More teaching $(\mathrm{T})$ & 25 & 17 & 12 & 28 & 18 & 24 \\
\hline \multicolumn{7}{|l|}{ b. Preferences } \\
\hline Primarily research (RR) & 7 & 12 & 34 & 14 & 22 & 26 \\
\hline Both, towards research (R) & 59 & 66 & 45 & 58 & 54 & 54 \\
\hline Both, towards teaching $(\mathrm{T})$ & 30 & 20 & 21 & 23 & 21 & 15 \\
\hline Primarily teaching (TT) & 4 & 2 & 1 & 5 & 3 & 5 \\
\hline \multicolumn{7}{|l|}{ c. Orientation } \\
\hline Theory high, practice low (Tp) & . & 33 & . & 24 & . & 39 \\
\hline Theory and practice high (TP) & . & 25 & . & 20 & . & 25 \\
\hline Theory and practice low (tp) & . & 20 & . & 34 & . & 17 \\
\hline Theory low, practice high (tP) & . & 22 & . & 22 & . & 19 \\
\hline
\end{tabular}

Source: CAP (March 2009).

professors, who leaned more strongly towards research in 1992, moved somewhat towards teaching. No clear trend in either direction holds true for university professors in the United Kingdom.

Finally, Table 1 shows that the professors' orientations towards theory or practice in their academic work are, to a lesser extent, concentrated on a single category. Not surprisingly, a strong emphasis on research combined with a low emphasis on practice is the most frequent orientation.

\section{Links between academic profiles and the actual professional life according to the 2007 survey}

Socio-biographic characteristics and the academic profiles

As regards socio-biographic profiles, Table 2 shows that strongly researchoriented professors are slightly younger than the average. As the study does not suggest a clear trend over time, we might assume that professors' orientations and activities shift somewhat towards teaching in the course of their careers.

A relationship seems to exist, although it is not consistent across all measures employed, between an academic family environment and a research orientation. First, many research-oriented professors have a partner who is also an academic. 
Table 2. Socio-biographical characteristics of university professors in Germany, Japan and the United Kingdom by teaching and research profile in 2007 (percentages and means)

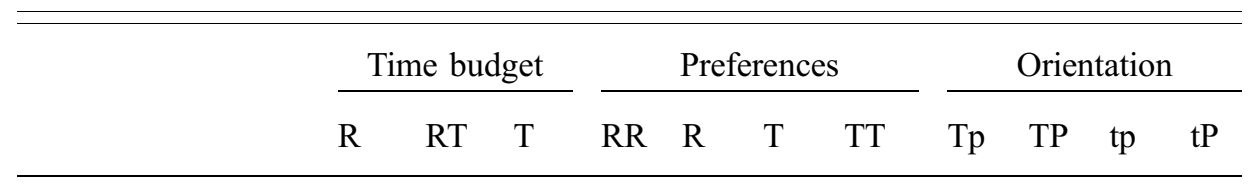

a. Germany

Age (mean years)

Male

Female

Total

Home citizenship

Foreign citizenship

Citizenship at birth

Academic partner

No academic partner

All with partner

$53 \quad 53$

$85 \quad 81$

$15 \quad 19$

$100 \quad 100$

$91 \quad 94$

9

$100 \quad 100$

$29 \quad 2$

$71 \quad 76$

$100 \quad 100$

\section{$52 \quad 50$}

7579

25

100

$\begin{array}{llll}5 & 21 & 18 & 21\end{array}$

$\begin{array}{llll}100 & 100 & 100\end{array}$

$485 \quad 88$

$\begin{array}{llll}88 & 93 & 82 & (100)\end{array}$

$\begin{array}{llll}12 & 7 & 8 & -\end{array}$

$\begin{array}{lllll}(54) & 51 & 55 & 53 & 52\end{array}$

$\begin{array}{lllll}(83) & 84 & 80 & 77 & 84\end{array}$

$\begin{array}{rrrrr}(17) & 16 & 20 & 23 & 16 \\ (100) & 100 & 100 & 100 & 100\end{array}$

\section{b. Japan}

Age (mean years)

Male

Female

Total

Academic partner

No academic partner

All with partner

Father HE

Father no HE

Total

Mother HE

Mother no HE

Total

\section{c. United Kingdom}

Age (mean years)

Male

Female

Total

Home citizenship

Foreign citizenship

Citizenship at birth

$\begin{array}{rrrrrrrrrrr}52 & 53 & 52 & 50 & 52 & 55 & (56) & 51 & 53 & 53 & 52 \\ 99 & 91 & 86 & 92 & 93 & 89 & (89) & 92 & 94 & 89 & 95 \\ 1 & 9 & 14 & 8 & 7 & 11 & (11) & 8 & 6 & 11 & 5 \\ 100 & 100 & 100 & 100 & 100 & 100 & (100) & 100 & 100 & 100 & 100\end{array}$

3

$97 \quad 95$

\section{$5 \quad 6$}

$100 \quad 100$

$94 \quad 95$

\section{$\begin{array}{lll}5 & 5 & 4\end{array}$}

(2)

$\begin{array}{rrrr}94 & 94 & 94 & 97\end{array}$

$48 \quad 50$

5250

$100 \quad 100$

46

$\begin{array}{lll}95 & 95 & 96\end{array}$

(100)

\section{$26-32-26$}

$\begin{array}{rrrrrrrrrrr}26 & 32 & 26 & 33 & 31 & 27 & (22) & 34 & 24 & 29 & 29 \\ 74 & 68 & 74 & 67 & 69 & 73 & (78) & 64 & 76 & 71 & 71 \\ 100 & 100 & 100 & 100 & 100 & 100 & (100) & 100 & 100 & 100 & 100\end{array}$

Academic partner

No academic partner

$\begin{array}{rrrrrrrrrrr}50 & 51 & 52 & 49 & 51 & 55 & (53) & 51 & 52 & 50 & 51 \\ 71 & 68 & 62 & 59 & 69 & 66 & (67) & 71 & 71 & 50 & 63 \\ 29 & 32 & 38 & 41 & 31 & 34 & (33) & 29 & 29 & 50 & 37 \\ 100 & 100 & 100 & 100 & 100 & 100 & (100) & 100 & 100 & 100 & 100\end{array}$

$\begin{array}{lllllllllll}77 & 75 & 92 & 72 & 78 & 88 & (89) & 67 & 75 & 85 & 91\end{array}$

$\begin{array}{lllllllllll}23 & 25 & 8 & 28 & 22 & 12 & (11) & 33 & 25 & 15 & 9\end{array}$

$\begin{array}{lllllllllll}100 & 100 & 100 & 100 & 100 & 100 & (100) & 100 & 100 & 100 & 100\end{array}$

$\begin{array}{lllllllllll}34 & 33 & 35 & 41 & 35 & 29 & (8) & 43 & 36 & 33 & 25\end{array}$

$\begin{array}{lllllllllll}66 & 67 & 65 & 59 & 65 & 71 & (92) & 57 & 64 & 67 & 75\end{array}$


Table 2. Continued

\begin{tabular}{|c|c|c|c|c|c|c|c|c|c|c|c|}
\hline & \multicolumn{3}{|c|}{ Time budget } & \multicolumn{4}{|c|}{ Preferences } & \multicolumn{4}{|c|}{ Orientation } \\
\hline & $\mathrm{R}$ & RT & $\mathrm{T}$ & $\mathrm{RR}$ & $\mathrm{R}$ & $\mathrm{T}$ & TT & $\mathrm{Tp}$ & TP & tp & $\mathrm{tP}$ \\
\hline All with partner & 100 & 100 & 100 & 100 & 100 & 100 & $(100)$ & 100 & 100 & 100 & 100 \\
\hline Father HE & 38 & 37 & 25 & 39 & 36 & 27 & (22) & 42 & 20 & 34 & 36 \\
\hline Father no HE & 62 & 63 & 75 & 61 & 64 & 73 & (78) & 58 & 80 & 66 & 64 \\
\hline Total & 100 & 100 & 100 & 100 & 100 & 100 & $(100)$ & 100 & 100 & 100 & 100 \\
\hline Mother HE & 28 & 29 & 16 & 29 & 27 & 15 & (11) & 32 & 16 & 21 & 24 \\
\hline Mother no HE & 72 & 71 & 84 & 71 & 73 & 85 & (89) & 68 & 84 & 79 & 76 \\
\hline Total & 100 & 100 & 100 & 100 & 100 & 100 & (100) & 100 & 100 & 100 & 100 \\
\hline
\end{tabular}

Second, research-oriented and research-active university teachers in the United Kingdom often have higher education-trained parents; in Japan, this is only true for research-oriented professors, while in Germany no significant links of this type exist.

Female professors are often strongly research-oriented, but many of them spend considerable time on teaching. This contrast suggests that there is a considerable number of female professors 'involuntarily' spending significant time on teaching and related activities.

Table 2 also shows that foreign university professors in the United Kingdom are more often research-oriented and often spend more time on research than their British colleagues. In Germany, foreign professors also are more often research-oriented, but they actually spend more time on teaching and teachingrelated activities than their German colleagues. The latter finding, again, might indicate that foreign university professors might be pushed against their inclinations toward a strong involvement in teaching (foreign professors in Japan have not been identified in the Japan survey because only few professors in Japan are foreigners).

Finally, we note a few links between theoretical versus practical orientation and the socio-biographic profile. Foreigners are more often theoretically oriented; strongly theoretically oriented but not practice-oriented professors often have a partner working as academic and often have higher education-trained parents.

\section{Variations of academic life according to academic profiles}

University professors' teaching versus research affiliation actually has an impact on their academic life. As Table 3 shows, teaching-oriented and teaching-active university professors work a few hours less per week. Surprisingly though, more teaching-active and teaching-oriented professors than those emphasizing research 
Table 3. Academic life of university professors in Germany, Japan and the United Kingdom by teaching and research profile 2007 (percentages)

\begin{tabular}{|c|c|c|c|c|c|c|c|c|c|c|c|}
\hline & \multicolumn{3}{|c|}{ Time budget } & \multicolumn{4}{|c|}{ Preferences } & \multicolumn{4}{|c|}{ Orientation } \\
\hline & $\mathrm{R}$ & RT & $\mathrm{T}$ & $\mathrm{RR}$ & $\mathrm{R}$ & $\mathrm{T}$ & $\mathrm{TT}$ & $\mathrm{Tp}$ & $\mathrm{TP}$ & tp & $\mathrm{tP}$ \\
\hline \multicolumn{12}{|l|}{ a. Germany } \\
\hline Weekly working hours* & 55 & 52 & 52 & 49 & 54 & 51 & $(38)$ & 55 & 52 & 51 & 52 \\
\hline Other income** & 11 & 5 & 12 & 3 & 9 & 7 & $(37)$ & 5 & 16 & 5 & 9 \\
\hline Discipline/field affiliation*** & 91 & 95 & 94 & 82 & 96 & 92 & $(83)$ & 90 & 94 & 92 & 97 \\
\hline Job - considerable strain*** & 43 & 49 & 62 & 53 & 48 & 50 & $(67)$ & 42 & 54 & 63 & 42 \\
\hline Job satisfaction** & 84 & 79 & 45 & 79 & 78 & 62 & $(50)$ & 69 & 79 & 72 & 77 \\
\hline \multicolumn{12}{|l|}{ b. Japan } \\
\hline Weekly working hours* & 52 & 51 & 47 & 50 & 52 & 47 & 47 & 52 & 53 & 50 & 49 \\
\hline Other income ${ }^{* *}$ & 8 & 2 & 2 & 7 & 3 & 2 & 3 & 2 & 6 & 2 & 2 \\
\hline Discipline/field affiliation*** & 94 & 94 & 90 & 97 & 95 & 89 & 79 & 96 & 95 & 92 & 95 \\
\hline Job - considerable strain $* * *$ & 62 & 55 & 60 & 56 & 57 & 56 & 66 & 57 & 66 & 55 & 53 \\
\hline Job satisfaction** & 78 & 69 & 60 & 67 & 70 & 73 & 68 & 68 & 75 & 63 & 76 \\
\hline \multicolumn{12}{|l|}{ c. United Kingdom } \\
\hline Weekly working hours* & 50 & 49 & 47 & 49 & 49 & 46 & 41 & 48 & 51 & 46 & 48 \\
\hline Other income** & 7 & 7 & 11 & 6 & 7 & 11 & 12 & 6 & 6 & 10 & 11 \\
\hline Discipline/field affiliation $* * *$ & 87 & 87 & 78 & 84 & 87 & 84 & 47 & 88 & 87 & 77 & 85 \\
\hline Job - considerable strain*** & 56 & 66 & 66 & 65 & 61 & 61 & 45 & 66 & 66 & 58 & 55 \\
\hline Job satisfaction** & 62 & 50 & 37 & 57 & 48 & 45 & 55 & 54 & 48 & 41 & 50 \\
\hline
\end{tabular}

*Based on responses when classes are in session $(60 \%)$, and when classes are not in session $(40 \%)$.

$* *$ Income from own university $=100$.

****Percentage.

( ) = Small absolute number of respondents in the respective column.

Source: CAP (March 2009).

view their jobs as a source of strain. This might indicate a different degree of job satisfaction. Actually, research-active professors are more often satisfied. As regards research-orientation, however, this only holds true for German professors.

Links between research versus teaching emphasis and additional income vary substantially by country. For research-oriented and research-active professors, side income is, on average, relatively higher in Japan. In contrast, teachingoriented and teaching-active professors have, on average, a higher side income in the United Kingdom. In Germany, the situation is less clear in this respect.

Finally, Table 3 shows that the theoretical versus practical orientation of university professors has little impact on the academic life as measured in this study. 
Variations of the teaching and research situation according to academic profiles

Table 4 shows the expected links between teaching versus research emphasis and academic's actual activities. Research-active and research-oriented professors receive more funds from external sources. They publish more frequently, also in a foreign language (the latter does not hold true for professors at universities in the United Kingdom). Research-active and research-oriented professors also more frequently carry out research in collaboration with others, also in collaboration with foreign colleagues. They serve more often academic committees on national or international level, and they are more often advocates of multi- and interdisciplinary research. Conversely, research-active and research-oriented professors are not very active in ICT-based/assisted teaching and learning activities, and they are also not very active in curriculum development.

A further finding deserves attention. University professors devoting most of their time to research less often consider teaching and research as hardly compatible tasks than professors spending about the same amount of time on teaching and research and those spending more time on teaching. Obviously, professors spending significant time on research are not highly concerned about the implications of this priority for teaching or are not pushed by their institution to increase their involvement in teaching. In contrast, substantial time spent on teaching is accompanied by the concern that research might suffer.

Table 5, finally, shows that various research activities mentioned above are most pronounced for university professors underscoring both theoretical and practical emphasis. In contrast, they are least pronounced for professors weakly oriented both to theory and practice.

\section{Academic profile and institutional life}

Table 5 shows that research-active professors rate the working environment more positively. This suggests that good working conditions are more often important for being actively involved in research and for being actively involved in teaching. As regards research-orientation, however, a similar finding can be reported only for Germany.

Strongly research-oriented professors seldom feel closely affiliated to their university. In contrast, strongly teaching-oriented professors often feel closely affiliated to their university. The middle-categories vary by country. In addition, the relationship between research/teaching activity and institutional affiliation is not consistent across countries and less varied than according to research/teaching orientation.

Teaching-oriented professors more often report personal influence on both faculty level and university level than research-oriented professors. There are not any similar links according to research/teaching activity except for the fact that 
Table 4. Teaching and research of university professors in Germany, Japan and the United Kingdom by teaching and research profile in 2007 (percentages)

\begin{tabular}{|c|c|c|c|c|c|c|c|c|c|c|c|}
\hline & \multicolumn{3}{|c|}{ Time budget } & \multicolumn{4}{|c|}{ Preferences } & \multicolumn{4}{|c|}{ Orientation } \\
\hline & $\mathrm{R}$ & RT & $\mathrm{T}$ & $\mathrm{RR}$ & $\mathrm{R}$ & $\mathrm{T}$ & TT & $\mathrm{Tp}$ & $\mathrm{TP}$ & tp & tP \\
\hline \multicolumn{12}{|l|}{ a. Germany } \\
\hline Teaching and research hardly compatible & 3 & 29 & 33 & 41 & 26 & 35 & $(60)$ & 33 & 17 & 38 & 28 \\
\hline ICT based/computer assisted learning & 12 & 23 & 23 & 6 & 22 & 23 & (17) & 20 & 21 & 11 & 33 \\
\hline Curriculum development & 45 & 67 & 75 & 55 & 60 & 75 & (33) & 65 & 61 & 65 & 59 \\
\hline Research work without collaboration & 59 & 64 & 79 & 68 & 64 & 65 & $(75)$ & 69 & 55 & 70 & 63 \\
\hline External research funding & 65 & 64 & 51 & 65 & 64 & 59 & (34) & 58 & 68 & 59 & 65 \\
\hline Multi/interdisciplinary research emphasis & 78 & 70 & 64 & 74 & 70 & 68 & $(50)$ & 66 & 92 & 56 & 63 \\
\hline Number of publications and reports* & 24 & 23 & 13 & 27 & 22 & 16 & (3) & 22 & 22 & 18 & 21 \\
\hline Serving as member of scientific committees & 60 & 49 & 32 & 57 & 50 & 45 & $(20)$ & 43 & 63 & 46 & 46 \\
\hline International research collaboration & 79 & 74 & 69 & 85 & 75 & 63 & $(25)$ & 86 & 78 & 63 & 62 \\
\hline Published in a foreign language & 69 & 52 & 40 & 72 & 55 & 40 & $(48)$ & 62 & 57 & 48 & 45 \\
\hline \multicolumn{12}{|l|}{ b. Japan } \\
\hline Teaching and research hardly compatible & 33 & 51 & 63 & 50 & 45 & 58 & $(68)$ & 49 & 41 & 56 & 47 \\
\hline ICT based/computer assisted learning & 26 & 34 & 41 & 25 & 33 & 34 & (35) & 26 & 36 & 35 & 37 \\
\hline Curriculum development & 19 & 27 & 41 & 17 & 27 & 33 & $(40)$ & 22 & 26 & 30 & 35 \\
\hline Research work without collaboration & 45 & 51 & 56 & 49 & 49 & 56 & $(60)$ & 51 & 49 & 55 & 46 \\
\hline External research funding & 64 & 49 & 38 & 65 & 54 & 32 & $(35)$ & 52 & 58 & 42 & 56 \\
\hline Multi/interdisciplinary research emphasis & 59 & 56 & 47 & 55 & 58 & 45 & $(42)$ & 60 & 70 & 38 & 56 \\
\hline Number of publications and reports* & . & . & & & . & . & & . & & . & \\
\hline Serving as member of scientific committees & 50 & 43 & 41 & 43 & 47 & 43 & $(33)$ & 40 & 55 & 38 & 54 \\
\hline International research collaboration & 34 & 26 & 14 & 38 & 28 & 11 & (6) & 37 & 36 & 16 & 19 \\
\hline Published in a foreign language & 56 & 41 & 31 & 50 & 45 & 30 & (28) & 51 & 44 & 38 & 36 \\
\hline
\end{tabular}


Table 4. Continued

\begin{tabular}{|c|c|c|c|c|c|c|c|c|c|c|c|}
\hline & \multicolumn{3}{|c|}{ Time budget } & \multicolumn{4}{|c|}{ Preferences } & \multicolumn{4}{|c|}{ Orientation } \\
\hline & $\mathrm{R}$ & RT & $\mathrm{T}$ & $\mathrm{RR}$ & $\mathrm{R}$ & $\mathrm{T}$ & TT & $\mathrm{Tp}$ & $\mathrm{TP}$ & tp & $\mathrm{tP}$ \\
\hline \multicolumn{12}{|l|}{ c. United Kingdom } \\
\hline Teaching and research hardly compatible & 23 & 23 & 33 & 32 & 18 & 30 & $(55)$ & 20 & 26 & 24 & 24 \\
\hline ICT based/computer assisted learning & 26 & 38 & 64 & 27 & 37 & 54 & (74) & 34 & 42 & 40 & 51 \\
\hline Curriculum development & 66 & 79 & 95 & 64 & 79 & 90 & (79) & 76 & 72 & 78 & 83 \\
\hline Research work without collaboration & 47 & 70 & 63 & 55 & 61 & 59 & $(70)$ & 61 & 64 & 63 & 45 \\
\hline External research funding & 76 & 65 & 43 & 77 & 68 & 51 & (36) & 63 & 75 & 58 & 74 \\
\hline Multi/interdisciplinary research emphasis & 72 & 61 & 60 & 78 & 64 & 48 & $(45)$ & 59 & 81 & 53 & 70 \\
\hline Number of publications and reports* & 17 & 11 & 7 & 18 & 11 & 6 & (3) & 13 & 13 & 8 & 14 \\
\hline Serving as member of scientific committees & 64 & 46 & 44 & 64 & 50 & 33 & $(25)$ & 51 & 55 & 37 & 58 \\
\hline International research collaboration & 86 & 74 & 60 & 83 & 82 & 54 & $(20)$ & 86 & 93 & 39 & 72 \\
\hline Published in a foreign language & 2 & 4 & 5 & 2 & 4 & 0 & (17) & 4 & 2 & 2 & 2 \\
\hline
\end{tabular}

*Number of scholarly books (co-)authored and (co-)edited, articles in books and journals, and research reports/monographs written for a funded project in the past three years.

( ) Small number of respondents in the respective column.

Source: CAP (March 2009). 
Table 5. Institutional life of university professors in Germany, Japan and the United Kingdom by teaching and research profile in 2007 (percentages)

\begin{tabular}{|c|c|c|c|c|c|c|c|c|c|c|c|}
\hline & \multicolumn{3}{|c|}{ Time budget } & \multicolumn{4}{|c|}{ Preferences } & \multicolumn{4}{|c|}{ Orientation } \\
\hline & $\mathrm{R}$ & RT & $\mathrm{T}$ & $\mathrm{RR}$ & $\mathrm{R}$ & $\mathrm{T}$ & $\mathrm{TT}$ & $\mathrm{Tp}$ & $\mathrm{TP}$ & tp & $\mathrm{tP}$ \\
\hline \multicolumn{12}{|l|}{ a. Germany } \\
\hline Perception of good work environment* & 55 & 48 & 39 & 52 & 50 & 42 & $(39)$ & 46 & 54 & 51 & 46 \\
\hline Affiliation to one's university & 47 & 50 & 42 & 41 & 51 & 43 & $(50)$ & 46 & 47 & 53 & 52 \\
\hline Personal influence on one's faculty & 60 & 65 & 62 & 45 & 67 & 60 & $(67)$ & 64 & 69 & 64 & 54 \\
\hline Personal influence on one's university & 34 & 28 & 13 & 19 & 30 & 20 & $(33)$ & 21 & 40 & 23 & 23 \\
\hline \multicolumn{12}{|l|}{ b. Japan } \\
\hline Perception of good work environment* & 34 & 28 & 24 & 32 & 28 & 26 & 31 & 30 & 30 & 25 & 26 \\
\hline Affiliation to one's university & 61 & 67 & 62 & 51 & 65 & 67 & 67 & 64 & 71 & 59 & 61 \\
\hline Personal influence on one's faculty & 33 & 33 & 29 & 19 & 33 & 34 & 43 & 30 & 34 & 29 & 34 \\
\hline Personal influence on one's university & 12 & 15 & 16 & 2 & 15 & 19 & 27 & 12 & 15 & 13 & 16 \\
\hline \multicolumn{12}{|l|}{ c. United Kingdom } \\
\hline Perception of good work environment* & 47 & 42 & 31 & 43 & 40 & 39 & 44 & 40 & 46 & 40 & 40 \\
\hline Affiliation to one's university & 43 & 34 & 33 & 36 & 37 & 44 & 50 & 38 & 34 & 47 & 35 \\
\hline Personal influence on one's faculty & 34 & 29 & 37 & 30 & 28 & 41 & 70 & 27 & 39 & 30 & 30 \\
\hline Personal influence on one's university & 9 & 12 & 8 & 9 & 9 & 23 & 25 & 8 & 17 & 14 & 8 \\
\hline
\end{tabular}

*Average rating of 1 or 2 on a scale of $1=$ Excellent to $5=$ Poor on 12 items (classroom, computer facilities, library facilities, secretarial support, research funding, etc.).

( ) = Small absolute number of respondents in the respective column.

Source: CAP (March 2009). 
teaching-active professors in Germany see themselves as having hardly any influence on university level.

Again, academics vary in their institutional life to a lesser extent according to their theoretical versus practical orientation than according to their teaching versus research emphasis. Moreover, differences by country come into play in this context.

\section{Changes over time in the links between academic profiles and professional life}

As pointed out, changes from the 1992 Carnegie survey to the 2007 CAP survey could only be identified in some of the areas addressed above. Changes over time could be measured regarding the time budget spent on teaching and research, as well as the preferences of teaching and research, because identical questions were posed in both surveys. In contrast, there were no questions posed in 1992 that were similar to those in 2007 regarding the theoretical and practical orientation of university professors.

As regards the 23 variables of socio-biographic characteristics, academic life, teaching and learning, and institutional life, which have been addressed in the previous sections, we note that only 11 have been asked in an identical or similar way in 1992. These 11 variables are presented in Table 6.

Altogether, we note that the views and the behaviour of university professors differ more strongly in various respects in 2007 than they had in 1992, both with respect to teaching versus research orientation and time spent on teaching and research. This can be interpreted as indicating a trend towards a more consistently diverse academic profession.

In one case, there is a clear shift of orientation over time. Both in Germany and the United Kingdom, job satisfaction was more strongly linked to research orientation and dominant research activity in 2007 than in 1992, while job satisfaction in Japan got closer to teaching. As university professors both in Germany and in the United Kingdom shifted their activities over this period more frequently towards research, and university professors in Japan more frequently towards teaching, we can conclude that in all three countries job satisfaction moved more strongly to the 'growth areas' of activities and orientations.

The comparison shows two differences reported above for 2007 that did not exist in 1992. First, while in 2007 good working conditions were reported more often by research-active university professors than by teaching-active professors, this distinction did not hold true in 1992. Second, while affiliation to one's university was more strongly expressed by teaching-active and teaching-oriented university professors in 2007 , the respective difference was substantially smaller in 1992. 
Table 6. Characteristics of professors in Germany, Japan and the United Kingdom by teaching and research profile in 1992

\begin{tabular}{|c|c|c|c|c|c|c|c|}
\hline & \multicolumn{3}{|c|}{ Time budget } & \multicolumn{4}{|c|}{ Preferences } \\
\hline & $\mathrm{R}$ & RT & $\mathrm{T}$ & $\mathrm{RR}$ & $\mathrm{R}$ & $\mathrm{T}$ & TT \\
\hline \multicolumn{8}{|l|}{ a. Germany } \\
\hline \multicolumn{8}{|l|}{ 1. Socio-biographic characteristics } \\
\hline Age (mean years) & 53 & 54 & 53 & 54 & 53 & 53 & $(54)$ \\
\hline Male & 93 & 96 & 91 & 98 & 95 & 95 & $(82)$ \\
\hline Female & 7 & 4 & 9 & 2 & 5 & 5 & (18) \\
\hline \multicolumn{8}{|l|}{ 2. Academic life } \\
\hline Weekly working hours* & 52 & 52 & 43 & 53 & 51 & 48 & (38) \\
\hline Discipline/field affiliation & 94 & 95 & 92 & 93 & 95 & 94 & (92) \\
\hline Job - considerable strain & 46 & 41 & 40 & 53 & 44 & 32 & 35 \\
\hline Job satisfaction & 62 & 68 & 54 & 55 & 63 & 69 & 61 \\
\hline \multicolumn{8}{|l|}{ 3. Teaching and research } \\
\hline Number of publications and reports** & 25 & 20 & 17 & 29 & 22 & 15 & 6 \\
\hline \multicolumn{8}{|l|}{ 4. Institutional life } \\
\hline Perception of good work environment & 26 & 27 & 27 & 27 & 27 & 27 & 27 \\
\hline Affiliation to one's university & 42 & 48 & 46 & 28 & 46 & 51 & 52 \\
\hline Personal influence on one's faculty & 39 & 51 & 53 & 39 & 51 & 49 & 74 \\
\hline Personal influence on one's university & 9 & 15 & 11 & 10 & 11 & 15 & 14 \\
\hline \multicolumn{8}{|l|}{ b. Japan } \\
\hline \multicolumn{8}{|l|}{ 1. Socio-biographic characteristics } \\
\hline Age (mean years) & 51 & 51 & 53 & 50 & 52 & 52 & $(60)$ \\
\hline Male & 93 & 99 & 100 & 97 & 100 & 100 & $(100)$ \\
\hline Female & 1 & 1 & 0 & 3 & 0 & 0 & $(0)$ \\
\hline
\end{tabular}

Age (mean years)

Male

Weekly working hours*

Discipline/field affiliation

Job - considerable strain

3. Teaching and research

Number of publications and reports**

4. Institutional life

Perception of good work environmen

(c) one's university

Personal influence on one's university

b. Japan

Age (mean years)

Female
93
100
0 
Table 6. Continued

\begin{tabular}{|c|c|c|c|c|c|c|c|}
\hline & \multicolumn{3}{|c|}{ Time budget } & \multicolumn{4}{|c|}{ Preferences } \\
\hline & $\mathrm{R}$ & RT & $\mathrm{T}$ & RR & $\mathrm{R}$ & $\mathrm{T}$ & TT \\
\hline \multicolumn{8}{|l|}{ 2. Academic life } \\
\hline Weekly working hours* & 48 & 48 & 41 & 46 & 48 & 48 & (29) \\
\hline Discipline/field affiliation & 98 & 97 & 95 & 95 & 99 & 100 & (67) \\
\hline Job - considerable strain & 65 & 65 & 82 & 67 & 63 & 61 & (67) \\
\hline $\begin{array}{l}\text { Number of publications and reports** } \\
\text { 4. Institutional life }\end{array}$ & 35 & 32 & 22 & 34 & 37 & 17 & (13) \\
\hline Perception of good work environment & 32 & 33 & 33 & 33 & 33 & 33 & (33) \\
\hline Affiliation to one's university & 73 & 78 & 70 & 67 & 79 & 81 & (67) \\
\hline Personal influence on one's faculty & 62 & 64 & 69 & 56 & 69 & 59 & (33) \\
\hline Personal influence on one's university & 40 & 26 & 35 & 29 & 41 & 34 & $(0)$ \\
\hline Male & 95 & 95 & 92 & 92 & 96 & 93 & $(100)$ \\
\hline Female & 5 & 5 & 8 & 8 & 4 & 7 & $(0)$ \\
\hline \multicolumn{8}{|l|}{ 2. Academic life } \\
\hline Weekly working hours* & 53 & 50 & 50 & 53 & 50 & 49 & (43) \\
\hline Discipline/field affiliation & 94 & 97 & 97 & 92 & 94 & 96 & (75) \\
\hline Job - considerable strain & 45 & 48 & 53 & 53 & 47 & 48 & (36) \\
\hline Job satisfaction & 62 & 66 & 64 & 53 & 67 & 66 & (67) \\
\hline
\end{tabular}


Table 6. Continued

\begin{tabular}{|c|c|c|c|c|c|c|c|}
\hline & \multicolumn{3}{|c|}{ Time budget } & \multicolumn{4}{|c|}{ Preferences } \\
\hline & $\mathrm{R}$ & RT & $\mathrm{T}$ & $\mathrm{RR}$ & $\mathrm{R}$ & $\mathrm{T}$ & $\mathrm{TT}$ \\
\hline \multicolumn{8}{|l|}{ 3. Teaching and research } \\
\hline $\begin{array}{l}\text { Number of publications and reports** } \\
\text { 4. Institutional life }\end{array}$ & 26 & 22 & 14 & 29 & 22 & 12 & (8) \\
\hline Perception of good work environment & 29 & 29 & 30 & 30 & 29 & 30 & (27) \\
\hline Affiliation to one's university & 70 & 69 & 65 & 68 & 66 & 76 & $(92)$ \\
\hline Personal influence on one's faculty & 44 & 50 & 55 & 43 & 48 & 50 & (82) \\
\hline Personal influence on one's university & 25 & 23 & 30 & 21 & 24 & 19 & $(30)$ \\
\hline
\end{tabular}

*Based on responses when classes are in session $(60 \%)$ and when classes are not in session $(40 \%)$.

**Number of scholarly books (co-)authored and (co-)edited, articles in books and journals, and research reports/monographs written for a funded project in the past three years.

$(\mathrm{)}=$ Small absolute number of respondents in the respective column.

Source: CAP (March 2009). 


\section{Summary}

In comparing the views and attitudes of university professors in three countries with different academic traditions, i.e. Germany, Japan and the United Kingdom, we have noted a dominant pattern as far as the relationships between teaching and research are concerned. Many university professors in all three countries spent, more or less, as much time on research as on teaching, and many of them favour a close link between teaching and research, although their orientation is leaning somewhat more strongly to research. Such 'academic profiles', as they have been referred to in this study, are more frequent in Germany than in Japan and the United Kingdom. There are, however, notable minorities of professors predominantly active in teaching and predominantly active in research; there are also notable minorities emphasizing the link between teaching and research who lean more strongly towards teaching or who are clearly oriented towards research. In contrast, university professors clearly oriented towards teaching comprise only a marginal group.

The degree of homogeneity or diversity of the academic profiles of university professors (measured as research-leaning versus teaching-leaning orientations and activities) remained unchanged from 1992 to 2007. However, across all categories, we note that teaching and research orientations as well as teaching and research activities tend to converge. In Japan, where research was relatively high on the agenda in 1992, we observe a move towards teaching; in Germany and to some extent in the United Kingdom, where teaching was somewhat higher on the agenda in 1992, we observe a shift towards research.

Teaching and research orientations are somewhat more closely linked on average to various views and activities of the academic profession than the actual time spent on teaching and research. Both the time budget spent on teaching and research as well as the orientations towards teaching versus research are clearly more influential for the overall situation and the activities of university professors than differences in the theoretical versus applied emphasis of respondents.

In the majority of areas, the views and activities of academics were more clearly differentiated according to teaching-research orientations and activities in 2007 than they were in 1992. However, we might state that changes over time have been moderate.

The 2007 data show that some academics spend substantial time on teaching despite an orientation towards research. Further findings encourage us to conclude that there exist 'involuntarily teaching-active' persons, among which (over-proportionally) are many women and foreign professors. By and large, on average they view their professional life more negatively than university professors.

Altogether, research-oriented and research-active university professors have a more positive view of their situation and are more satisfied with their situation than teaching-oriented and teaching-active research-oriented professors. This does 
not hold true consistently though, and there are remarkable opposite findings, e.g. a stronger institutional affiliation of teaching-oriented university professors.

In conclusion, we note that university professors have room to shape their role, either more strongly towards research or towards teaching. Such strategic options are not just isolated views or activities, but are intertwined with the various ways in which they perceive their environment and in which they run their daily affairs. However, such links between strategic academic orientations and various elements of their experiences and activities were quite moderate in 1992. The links have increased somewhat over time, but it would be an exaggeration to claim that such strategic options have led to a clearly segmented inter-individual diversity of academic profiles.

\section{Acknowledgement}

The authors acknowledge the support of the Fondazione Compagnia di San Paolo.

\section{References}

1. J. Brennan, J. Enders, C. Musselin, U. Teichler and J. Välimaa (2008) Higher Education Looking Forward: An Agenda for Future Research (Strasbourg: European Science Foundation).

2. U. Teichler (2007) Higher Education Systems, Conceptual Frameworks, Comparative Perspectives, Empirical Findings (Rotterdam and Taipei: Sense Publishers).

3. U. Teichler (2008) Diversification? Trends and explanations of the shape and size of higher education. Higher Education, 56, 349-379.

4. See the overview in V. L. Meek, L. C. J. Goedegebuure, O. Kivinen and R. Rinne (eds) (1996) The Mockers and Mocked: Comparative Perspectives on Differentiation, Convergence and Diversity in Higher Education (Oxford: Pergamon/IAU Press).

5. M. Trow (1974) Problems in the transition from elite to mass higher education. Policies for Higher Education, edited by OECD (Paris: OECD), pp. 51-101.

6. J. S. Taylor, J. B. Ferreira, M. de Lourdes Machado and R. Santiago (eds) (2008) Non-University Higher Education in Europe (Dordrecht: Springer).

7. J. Huisman (2009) The Bologna Process towards 2020: institutional diversification or convergence. In: The European Higher Education Area: Perspectives on a Moving Target, edited by B. M. Kehm, J. Huisman and B. Stensaker (Rotterdam and Taipei: Sense Publishers), pp. 245-262.

8. B. R. Clark (1996) Diversification of higher education, viability, and change. In: The Mockers and Mocked: Comparative Perspectives on Differentiation, Convergence and Diversity in Higher Education, edited by V. L. Meek, L. C. J. Goedgebuure, O. Kivinen and R. Rinne (Oxford: Pergamon/IAU Press), pp. 17-25.

9. M. Gibbons, C. Limoges, H. Nowotny, S. Schwartzman, P. Scott and M. Trow (1994) The New Production of Knowledge: The Dynamics of Science and Research in Contemporary Societies (London: Sage). 
10. J. Välimaa (2009) The relevance of higher education to knowledge society and knowledge-driven economy: education, research and innovation. In: The European Higher Education Area: Perspectives on a Moving Target, edited by B. M. Kehm, J. Huisman and B. Stensaker (Rotterdam and Taipei: Sense Publishers), pp. 23-41.

11. T. Becher and P. R. Trowler (2001) Academic Tribes and Territories: Intellectual Enquiry and the Cultures of Disciplines, 2nd edn (Buckingham: SRHE \& Open University Press).

12. C. Kerr (1963) The Uses of the University (Cambridge, MA: Harvard University Press).

13. See various articles in J. Enders (ed.) (2001) Academic Staff in Europe: Changing Contexts and Conditions (Westport, CT and London: Greenwood Press).

14. U. Teichler (ed.) (2007) The Formative Years of Scholars (London: Blackwell Press).

15. J. Enders and U. Teichler (1995) Der Hochschullehrerberuf im internationalen Vergleich (Bonn: Bundesministerium für Bildung, Wissenschaft, Forschung und Technologie).

16. P. G. Altbach (ed.) (1996) The International Academic Profession: Portrait of Fourteen Countries (Princeton, NJ: Carnegie Foundation for the Advancement of Teaching).

17. P. A. M. Maassen and Frans A. van Vught (eds) (1996) Inside Academia: New Challenges for the Academic Profession (Utrecht: Uitgeverij De Tijdstroom).

18. First results are published in The Changing Academic Profession in International Comparative and Quantitative Perspectives (2008) (Hiroshima: Research Institute for Higher Education, Hiroshima University).

\section{About the Author}

Ulrich Teichler has been professor at the International Centre for Higher Education Research, University of Kassel (Germany) since 1978 and for 16 years served as the Centre's Director. He studied sociology at the Free University of Berlin, was a researcher at the Max Planck Institute for Educational Research, Berlin, and earned his $\mathrm{PhD}$ with a dissertation on higher education in Japan (University of Bremen). He has had extended research periods in Japan, the Netherlands and the US, and academic visits to more than 70 countries. He has also had visiting professorships at Northwestern University, College of Europe, Hiroshima University, and the Open University, UK. His main research areas include higher education and the world of work, comparison of higher education systems, and international mobility in higher education. He has authored more than 1000 publications. He is a member of the International Academy of Education and the Academia Europaea, former chairman of the Consortium of Higher Education Researchers, former president and distinguished member of EAIR, and fellow of the Society for Research into Higher Education. He was awarded the Research Prize of CIEE and the Comenius Prize of UNESCO and holds a Dr h.c. of the University of Turku. 